This item was submitted to Loughborough's Research Repository by the author.

Items in Figshare are protected by copyright, with all rights reserved, unless otherwise indicated.

\title{
The impact of video feedback on professional youth football coaches' reflection and practice behaviour: a longitudinal investigation of behaviour change
}

\section{PLEASE CITE THE PUBLISHED VERSION}

http://dx.doi.org/10.1080/14623943.2015.1071707

\section{PUBLISHER}

(C) Taylor \& Francis

\section{VERSION}

AM (Accepted Manuscript)

\section{PUBLISHER STATEMENT}

This work is made available according to the conditions of the Creative Commons Attribution-NonCommercialNoDerivatives 4.0 International (CC BY-NC-ND 4.0) licence. Full details of this licence are available at: https://creativecommons.org/licenses/by-nc-nd/4.0/

\section{LICENCE}

CC BY-NC-ND 4.0

\section{REPOSITORY RECORD}

Partington, Mark, Christopher J. Cushion, Ed Cope, and Stephen Harvey. 2019. "The Impact of Video Feedback on Professional Youth Football Coaches' Reflection and Practice Behaviour: A Longitudinal Investigation of Behaviour Change". figshare. https://hdl.handle.net/2134/20637. 


\section{The impact of video feedback on professional youth football coaches' reflection and} practice behaviour: a longitudinal investigation of behaviour change

\section{Mark Partington, Christopher J. Cushion, Ed Cope \& Stephen Harvey}

a Department of Sport and Physical Activity, Edge Hill University, Ormskirk, UK

b School of Sport, Exercise and Health Sciences, Loughborough University, Loughborough,

UK

c Department of Sport, Health and Exercise Science, University of Hull, Hull, UK

$\mathrm{d}$ Department of Coaching and Teaching Studies, West Virginia University, Morgantown,

Abstract

The aim of this study was to investigate the impact of video feedback on five English youth football coaches' reflection and practice behaviours over a three season period. First, quantitative data were collected using the Coach Analysis and Intervention System (CAIS) during season one and season three. Data from CAIS results showed that over the three seasons the coaches decreased their total instruction and total feedback and increased silence 'on-task'. Four out of the five coaches also increased the use of total questioning behaviour. Second, interviews revealed how video feedback gave structure to reflective conversations that improved self-awareness and provided a trigger for behaviour change. The coaches highlighted how video-based reflection challenged their current understanding and enabled a range of learning sources to support and inform changed coach behaviour.

\section{Introduction}

27 In professional football, there remains an underlying sub-culture that has a pervasive and influential effect on coaches and their behaviour (e.g., Cushion \& Jones, 2006; Roderick, 2006). Indeed, research has identified a 'traditional' approach to coaching that is highly directive, autocratic and prescriptive (e.g., Harvey, Cushion, \& Massa-Gonzalez, 2010; Potrac \& Cassidy, 2006; Williams \& Hodges, 2005). Patterns of coaching behaviour tend to be relatively stable, with evidence showing that only minor differences exist as a function of

33 the age or skill level of the players coached (Cushion, Ford \& Williams, 2012; Ford, Yates, \&

34 Williams 2010; Partington, Cushion \& Harvey, 2013). While illustrating what coaches do, 
behavioural research has also demonstrated two key things. First, that coaches have limited awareness of what behaviours they use, and how often they use them, (Harvey, Cushion, 37 Cope \& Muir, 2013; Partington \& Cushion, 2013) and second, that an 'epistemological gap' exists between underpinning knowledge and coach behaviour (Partington \& Cushion, 2013; Partington et al., 2013). As a result, advances in coach education would seem fruitless if coaches lack self-awareness and understanding of their behaviour, particularly in practice environments driven by a strong sub-culture, such as professional football.

Changing established practice can be problematic particularly as coaching in football

43 lacks a critical tradition (Cushion, Armour \& Jones, 2003). As such, coaches are more likely 44 to be seen sticking with safer, tried and tested, traditional methods that prove their knowledge and expertise (Cushion et al., 2012; Potrac, Jones, \& Cushion, 2002). There remains a considerable challenge to address coaches' embodied and unarticulated beliefs. For actual change to happen to coaches' behaviour requires more than just obtaining additional knowledge (Harvey et al., 2010). A key in challenging entrenched practice cultures is providing a catalyst for changing what coaches do through reflection (Cushion et al., 2012). However, this is particularly challenging using short formal coach education episodes as coaches only acquire some of their knowledge and skills from such courses (Cushion et al., 2012). The remainder is acquired through 'apprenticeships of observation' as athletes, experiential learning and mentoring (Cushion et al., 2003; Erickson, Côté, \& Fraser-Thomas, 2007; Williams \& Hodges, 2005). Therefore, in order for coaches to recognise and address their deeply embedded beliefs and behaviour, prolonged interaction in a contextualised setting supported with continuous reflection on their practice is required (Thompson \& Pascal, 2012). However, a coach simply experiencing coaching will not necessarily lead to the development of new knowledge (Gilbert \& Trudel, 2006), nor is reflective practice merely a process of requiring learners 'to pause for thought from time-to-time' (Thompson \& 60 Pascal, 2012, p. 311).

A number of researchers (e.g., Ghaye, 2001; Gilbert \& Trudel, 2001; Irwin, Hanton, \& Kerwin, 2004; Knowles, Gilbourne, Borrie, \& Nevill, 2001; Nelson \& Cushion, 2006, inter-alia) have shown the importance of reflective practice in coach learning. There are many types of reflection (e.g., descriptive, creative; Ghaye, 2001), but in order to change practice critical reflection is required (Cushion et al., 2012). The ability to engage in critical reflection (i.e., questioning and challenging current practice, habits, routines, values and beliefs) is a

67 key process for a coach in this situation, and is the method by which coaches come to 68 question what they do and why (Knowles et al., 2001). Coaching is the combination of 
69 thought with action. It is important therefore not to just look at observable behaviour and

70 practice or focus on cognition in isolation, but consider their relationship and interaction in

71 practice (Cushion et al., 2012). In addition, coaching and coach education experiences unfold

72 over time and viewed with this temporal quality, learning is well underway before any

73 coaching course or CPD session begins and continues after it has finished (Hager \&

74 Hodkinson, 2009), thus confirming the need to consider coach learning as a more long-term

75 endeavour. In other words, coaching practice and coaches' reflection needs to be considered

76 longitudinally, not as one-off discrete episodes.

77 Learning through observation and experience can promote and reinforce certain

78 ideological interpretations of knowledge and practice, resulting in practice being guided by

79 uncritical inertia, with outdated knowledge and behaviours being passed on and reproduced

80 by other coaches (Cushion et al., 2012). Consequently, coaches need to reflect critically and

81 make judgements that are meaningful within their particular situation and challenge, rather

82 than reinforce certain beliefs or practices. To enable this, coaches need to engage with, and

83 develop 'tools' that encourage continual self-reflection and evaluation. One such tool is

84 video-based feedback, which offers the potential to generate and support reflection that

85 facilitates deep learning by bringing tacit mental processes to consciousness and

86 conceptualising practice then integrating altered and developed theory into action (Carson,

87 2008; Trudel, Gilbert, \& Tochon, 2001). Using video clips of coaches' actual practice and

88 engaging in reflective conversation is underpinned by a social constructivist view of learning.

89 Carefully examining the thought processes, knowledge, reasoning and learning behind

90 coaches practice offers the potential to raise self-awareness, spark critical reflection and

91 generate behaviour change (Partington \& Cushion, 2013; Schön, 1983; Trudel et al., 2001).

92 Therefore, the aim of this study was to take a longitudinal approach to investigate

93 changes (or stability) in coaches' practice over time, and understand how video-based

94 feedback can inform coaches' interpretations of their experiences; and generate critical

95 reflection on the process by which meaning and knowledge are used to guide actions (Harvey

96 et al., 2010; Potrac et al., 2002). The objective was to not only gain insight into changes in

97 coach behaviour over time but also understand the impact of video-based feedback and how

98 these intersect with, and inform, coaches' reflective practice.

99

100 Methodology

101 Research context 
102 Football talent development in England is managed by professional clubs to produce players

103 for the professional game (The Premier League Elite Player Performance Plan (EPPP), 2011).

104 Players are scouted and contracted to play for clubs from the age of eight and attend an

105 Academy. Football Academies deliver the youth football performance pathway, which

106 comprises three distinct phases, the foundation phase (under 5 to under 11), the youth

107 development phase (under 12 to under 16) and the professional development phase (under 17

108 to under 21) (EPPP, 2011). Academies provide a programme of coaching, games, sports 109 science support and education for players across the phases, to 'create a fully integrated

110 environment servicing all aspects of the players' development' (EPPP, 2011 p. 18).

111 Foundation phase players are provided with between 5 and 8 hours of coaching and weekend

112 competitive matches each week, increasing to between 12 and 16 hours in the youth

113 development phase. At the end of the development period players may be offered a

114 professional playing contract at the club. This study took place at a Football Association

115 (F.A.) Premier League Academy over three English football seasons.

\section{Participants}

118 All twelve male professional youth football coaches at one Football Association (F.A.)

119 Premier League Academy were purposefully sampled and took part in the study. However at

120 the end of the three English football seasons only five of the twelve coaches had completed

121 the longitudinal research process. Given the volatile nature of professional football it is not 122 uncommon for coaches to be replaced, or move on to other clubs. However, given that this 123 was a longitudinal study that aimed to investigate the complexities of coaching behaviour, the 124 reduction in sample size did not compromise the purpose of the study. The following section 125 provides an overview of the qualifications and characteristics of the five coaches involved in 126 the study.

\section{Tony (pseudonym)}

128 Tony coached the under 10's. He had a postgraduate level education in strength and conditioning, Post Graduate Certificate in Education*, a F.A. level 3 (UEFA B) coaching award and a full F.A. Youth Award*. Tony had four years coaching experience in this setting and another eight years professional coaching on Fundamental skills at participation level.

Pete (pseudonym)

134 Pete coached the under 12's. He had a F.A. level 3 (UEFA B) coaching award and a full F.A. 135 Youth Award*. He had been coaching for 12 years of which 4 have been spent in this setting. 
Jude (pseudonym)

138 Jude coached the under 14's. He had ten years coaching experience of which five years was

139 in the current setting. He had a postgraduate level qualification in sports coaching, Post

140 Graduate Certificate in Education, a F.A. level 3 (UEFA B) coaching award and a full F.A.

141 Youth Award*.

143 Ian (pseudonym)

144 Ian coached the under 11's with Lee in an official equal role. He had a degree level 145 qualification, a F.A. level 3 (UEFA B) coaching award and a full F.A. Youth Award*. Ian 146 was a former youth team player at another club eight years previous and had four years 147 coaching experience all in this setting.

\section{Lee (pseudonym)}

150 Lee coached the under 11's. He had eleven years coaching experience, three years in the current setting and six years at two other professional football clubs in youth development.

152 Lee had played semi-professional football and was a Further Education lecturer on a sports 153 programme. His qualifications included a degree level qualification, a Post Graduate

154 Certificate in Education, a F.A. level 3 (UEFA B) coaching award and a full F.A. Youth 155 Award*.

\section{Research Overview}

158 A mixed methods case study approach was employed as it had the potential to understand and explain the 'case' in more depth than a single method approach; qualitative data were used to support quantitative data and vice versa (Creswell, 2003; Stark \& Torrance, 2005). Case studies should be used in instances where how and why questions are being asked, as well as 'what' questions (Leech \& Onwuegbuzie, 2007; Yin, 1994). These apply to the current study, as it attempted to understand the connection between coaches' experiences, reflection and their practice, a similar approach adopted by Jones, Armour and Potrac's (2004) case study investigating the pedagogical practices of elite sport coaches.

The research started with twelve football coaches as participants (all the coaches available in this particular setting) however the longitudinal nature of the study (three seasons) and the turnover of coaching staff meant that only five completed the study in its entirety. Previous research (e.g. Harvey et al., 2013) suggests that participant numbers 
between 3-5 is acceptable for 'understanding the various nuances, contrasts and patterns of coach behaviour' and allowed 'situational diversity necessary for identifying thematic 172 patterns' (p. 4).

During season one the coaches practice sessions were filmed. At the end of season

174 one, individual interviews took place with the lead researcher and provided the opportunity

175 for coaches to watch their coaching, look at their observational data and discuss their

176 practice. The semi-structured nature of this process gave each coach freedom to discuss the 177 footage and observational data that was perceived as most useful or of most importance. The 178 coaches were also given the videos and the observational data to review in their own time. 179 This strategy gave coaches ownership of the process and helped develop motivation to 180 change (Meeus, Serpa \& Cuyper, 2010). During season two, the coaches undertook 'in181 house' coach education including a workshop to discuss their beliefs about coaching. They 182 also completed formal coach education in the form of the F.A. Youth Award level one as well 183 as sporadic discussions on their coaching practice with an F.A. coach educator. In between seasons two and three the coaches completed a further formal course, the F.A. Youth Award level two. During season three, the coaches again completed formal coach education, the F.A. Youth Award level three including assessment, while undertaking the same data collection protocol described for season one.

\section{Procedures}

190 Systematic observation

191 The primary behaviours of the Coach Analysis and Intervention System (CAIS) (see 192 Cushion, Harvey, Muir \& Nelson, 2012) were used to identify the five coaches' practice 193 behaviour. This systematic observation tool has been used in a number of studies (e.g. 194 Harvey et al., 2013; Partington \& Cushion, 2013; Partington et al., 2013) providing objective, 195 valid and reliable coach behaviour data. After ethics committee approval and participant's 196 informed consent, each coach was filmed in season one and three a minimum of three times 197 (Brewer \& Jones, 2002) with an average duration of $M=74.20$ minutes observation per session. The three systematic observations were spread out over the length of the season 199 (September to March) to provide an accurate representation of the individual coaches' 200 behaviour (Potrac et al., 2002). In total 30 coaching sessions were observed over the three 201 seasons. Inter- and Intra- observer reliability checks were completed in line with 202 Baumgartner, Jackson, Mahar and Rowe's (2007) recommendation that $30 \%$ of the sample 203 should be re-coded. Intra-observer and inter-observer were calculated using the equation: 
204 (agreements / (agreements + disagreements)) x 100 (van der Mars, 1989). Inter-observer 205 agreement was $90 \%$ and intra-observer was $97 \%$ for the coach behaviour data. These figures 206 are above the recommended $85 \%$ regarded as acceptable reliability agreement scores (van der 207 Mars, 1989).

\section{Interviews}

210 Systematic observation provided detail on what behaviour coaches' used in practice, while 211 the interviews explored the why of the behaviours as well as the coaches coaching 212 experiences across the three seasons. Three semi-structured interviews (see table 1) took 213 place with each coach. First after season one and two exploring coaches' behaviour (i.e. what 214 behaviour do you use most in your coaching? Why do you use this behaviour most in your 215 coaching?), and coaches' biographies and backgrounds (i.e. how long have you been 216 coaching? What coach education awards do you have?). After season three the interviews 217 examined the changes (or not) in their coaching behaviour and practice and possible reasons 218 for changes (or not). During the first and third interview behavioural data were presented to 219 each coach individually. In total 15 interviews were carried out with each interview lasting 220 between 30 and 70 minutes and produced 149 pages of interview transcript data. The reason 221 for the variance in interview minutes was that some were initial interviews and others were 222 follow up interviews.

\section{Data analysis}

225 Coaching behaviours

226 Coaches' behaviour was coded and quantified based on operational definitions (See Cushion 227 et al., 2012). Doing this gave the total frequency for individual coaching behaviours used, 228 which then allowed percentages to be calculated. Percentages were calculated by dividing the 229 frequency of individual behaviours by the total number of all behaviours. Descriptive data 230 were calculated for each coach.

Interview data

233 The coaches' interviews were transcribed and analysed thematically. Patterns or 'themes' 234 were identified through recursively reviewing the data (Glaser \& Strauss, 1967), a process of 235 'moving backwards and forwards between the data set' using a constant comparative 236 approach (Braun \& Clarke, 2006, p.86). Given the initial structure from the CAIS and at the 237 same time the exploration of themes in the data the analysis process was not entirely 
238 inductive, or deductive. Rather an abductive analysis was adopted that considers how data

239 impacts on theory, but also how theory impacts on data (Morgan, 2007; Nelson \& Cushion, 240 2006).

\section{1}

\section{Results}

243 Results from the individual coaches systematic observations are presented in the following 244 section.

\section{Systematic Observation}

246 Tony

247 In season one three behaviours comprised almost 58.09\% of Tony's total behaviours. Of

248 these, management was the highest at $31.80 \%$, followed by concurrent instruction at $13.37 \%$

249 and then general feedback positive at 12.92\% (see table 1). In season three these three

250 behaviours were again the most employed by Tony, however, because concurrent instruction

251 was considerably lower than in season 1 by $5.62 \%$, these behaviours combined equated to 252 less than they did in the first season at 53.30\% (see table 1). Tony's use of management and 253 general feedback positive were similar between the two seasons.

254

255 Pete

256 Pete's most employed behaviours were the same as Tony's, in that he mostly used $21.65 \%$ 257 management, $21.82 \%$ concurrent instruction and then $16.13 \%$ general feedback positive (see 258 table 1). In season one these behaviours equated again to almost $59.60 \%$ of Pete's total 259 behaviours. Whilst these three behaviours were maintained as the highest in season three at $26055.38 \%$, there was a change for each of these behaviours with management increasing 5.70\% 261 and concurrent instruction decreasing 5.42\% and general feedback positive decreasing $4.50 \%$ 262 (see table 2).

263

264 Jude

265 In the same way as Tony and Pete, in season one Jude adopted 23.05\% management, 17.42\% 266 concurrent instruction and $10.19 \%$ general feedback positive more than any other behaviour 267 totalling 50.66\% (see table 1). However, unlike Tony and Pete, Jude's behavioural profile 268 changed between season one and season three. So whilst management remained his highest 269 used behaviour at $26.59 \%$, concurrent instruction was lower in season three than it was in 270 season one by $11.94 \%$. Furthermore, Jude's use of specific feedback positive notably 
271 increased by $2.69 \%$ and in doing so became his second most employed behaviour in season

272 three, with convergent questioning at 9.26\% his third highest behaviour (see table 1).

273

274 Ian

275 Again, Ian's behavioural profile was the same as the three coaches' discussed already.

276 However, in season one, the combination of $16.29 \%$ management, $42.58 \%$ concurrent

277 instruction and $20.86 \%$ general feedback positive equated to $79.73 \%$ of the total behaviours

278 employed by Ian. Whilst these same three behaviours were also the highest in season three,

279 his amount of management went up by $7.70 \%$, but his use of concurrent instruction decreased

280 by $29.82 \%$, as did his use of general positive feedback by $6.94 \%$ (see table 1 ).

281

282 Lee

283 In slight contrast to the other four coaches, Lee's most employed behaviours were $27.85 \%$

284 management, $16.25 \%$ silence on-task, and 7.92\% general reinforcement positive. The amount 285 of concurrent instruction given by Lee was considerably less than that given by the other four 286 coaches (see table 1). The behavioural profile for Lee in season three was similar to that of 287 season one with the exception of confer with assistant that increased 5.69\% (see table 1).

Insert table 1 Here

290

291 While it was not the aim of this study to aggregate and compare the five coaches behaviour, 292 the presentation of the results in figure 1 allows an understanding of the changes in the 293 pattern of the coach's behaviour, and shows something of the impact of taking part in the 294 study (see figure 1).

\section{Interviews}

299 Results from the abductive analysis are presented in the following analysis and discussion 300 section as exemplar quotes. The key themes were:

301 - Video, self-awareness and reflection.

302 - Reflective conversation and its impact on practice. 
- Other learning and its impact on practice (e.g. FA Youth Awards, teaching qualification, social media, internet, observation of coaches and discussion with coaches).

\section{Analysis and Discussion}

\section{Video, self-awareness and reflection}

309 According to Cassidy (2010, p. 143), changing 'time-honoured practices' or 'day-to-day

310 conventions' in coaching is very difficult to achieve; this is because many coaches 'find it

311 difficult to reflect upon, and possibly critique, taken for granted practices that have become

312 integral to their sense of self'. Indeed, relying solely on ones' self-perception of what works

313 closes down conversations, blunts knowledge and stifles creativity, all of which, if left

314 unchallenged, produces stagnation and creates a climate of self-referential and self-justifying

315 knowledge structures (Abraham, Collins, \& Martindale, 2006). In the present study, the use of

316 video allowed coaches to move beyond their reliance on self-perceptions, which proved to be

317 an inaccurate account of their practice, and develop an increased self-awareness of what they

318 actually did. As Tony, Jude and Pete noted: 'Feedback from the first season, you don't realise

319 you're doing it until someone filmed you and told you. I thought I was coaching one way and

320 obviously I wasn't', 'I realised there that I wasn't quite behaving as a coach as I wanted' and

321 finally Pete 'watching yourself coach and looking at the different results I've got from the 322 different years, it opens your eyes'. Lee reinforced this view further linking to a particular behaviour:

The evidence in this case supports the need to use more objective methods that allow coaches

Yeah, I need to reduce my instructions. That's a big thing I'm surprised it's that high. I think with most teachers it's a thing, they talk a little bit too much, and looking at videos of myself coaching, that's apparent as well. So that's something I will have to work on. to reflect on their practice; deep learning, indicated by whether coaches intend to change or preserve their coaching practice, relies on reflection (Leduc, Culver, \& Werthner, 2012). Light, Evans, Harvey, \& Hassanin (2015) argue for informed reflection that bridges the gap between experience and coach education. In the present study, the research process resulted in the CAIS being used as a means of analysing what behaviours coaches employed, and using these data as a means to support reflection and discussions about individual's practice. Jude explained: 'looking at my actual behaviours, looking at the videos, actually that's the 
trigger of the learning and it helps me improve as a coach. It [the research process]

338 highlighted my behaviours'. Thus, the research process was in fact an intervention, where

339 video feedback sparked the reflective conversation process thus breaking the cycle of self-

340 reference and self-justification.

341 Over a decade ago, Trudel et al. (2001) found similar unexpected learning where

342 coaches naturally benefitted from reflecting on their practice from another perspective.

343 Trudel et al. (2001) explained that participants' learned through developing an ongoing

344 partnership between the researcher and coach that created a context for shared reflection, and

345 noted the value of video and shared reflection in the construction of coaching knowledge.

346 These findings resonate with the present study with data supporting Trudel et al.'s (2001)

347 claims in the context of professional youth football coaching. Pete and Ian stated:

These data suggest that reflection, using technology alongside opportunities to discuss their practice in light of the data, was a key strategy to enable coaches' beliefs and dispositions to be made explicit (Christensen, 2011) and also allow coaches the opportunity to become more aware of their practice (Gilbert \& Trudel, 2006).

\section{Reflective conversation and its impact on practice}

365 To develop as a practitioner requires thinking critically about practice (Butler, 2005).

366 However, there can be a divergence between perceptions and action, and educators and 367 practitioners need to pay attention to the gap (McCallister, Blinde, \& Weiss, 2000). In the 368 present study, video helped to avoid the risk of coaches unwittingly collecting evidence 369 corresponding to what they believed or expected to see, thus receiving self-confirmation of 370 their actions. Jude stated 'the video showed me clearly what I was doing when I coached' and 
371 Tony suggested 'someone else analyse and observe you and give you feedback rather than

372 just doing your own feedback and your own reviews. I think reviewing what you've done is

373 important'. The 'genuine feedback on the outcomes of action' afforded by video methods was

374 crucial in allowing practitioners to step 'outside their taken-for-granted world' (Eraut, 2000,

375 p. 123) and close the distance between practical theories-in-use and more abstract espoused

376 theories. In support of this claim, Jude reported that 'highlighting the behaviours has been

377 great for me in terms of it gives me an awareness of what behaviours I'm actually 378 implementing'.

379 Building on the work of Schön (1983), Gilbert and Trudel (2001) developed a reflective 380 conversation framework. This framework, acting through a coach's role frame, follows a 381 systematic process of identifying the issue that needs reflecting on, before working through a 382 number of potential strategies to solve the issue. The issues or dilemmas of practice are the 383 mechanism by which any reflection or engagement with experiential learning are triggered 384 (Gilbert \& Trudel, 2005; Schön, 1983). Pete highlighted:

Importantly, learning through coaching practice is more than the passive perception and internalisation of an external reality (Varela, Thompson, \& Rosch, 1991). It involves the projection of the individual's experiences and an act of interpretation shaped by that experience (Light, 2008). In other words, learning within a coaching environment cannot be reduced to a linear process of internalising pre-existing knowledge (Davis \& Sumara, 1997;

395 Light, 2008). In theories of experiential learning through reflection (e.g. Gilbert \& Trudel 396 2004; Schön, 1983), there remains an important interplay between experience and reflection. 397 Effective reflective practice involves careful consideration of both 'seeing' and action to 398 enhance the possibilities of learning through experience. Therefore, a process of learning 399 from reflection suggests that knowledge must become recognisable and articulated 400 (Loughran, 2002; Cushion \& Jones, 2006). This process is considerably more than 401 highlighting the problem and then providing the solution. There remains a subtle difference 402 between being told what to do and understanding practice (Loughran, 2002). This means that 403 experiencing situations in a certain way becomes a genuine learning experience, an episode 404 that carries personal meaning (White, 1988). This personal meaning appears key as a link to 
ownership of a reflective process, practitioners 'will pay more attention to information that 406 has immediate and personal meaning for them' (Gilbert \& Trudel, 2001, p. 32). As both Tony 407 and Lee highlight: 'seeing myself coach really rams home what I need to improve on' and

408 'looking back at the videos of my own coaching sessions helps me recognise the areas I want 409 to improve'. When working through potential strategies to solve an issue the coaches drew on 410 their knowledge as well as the knowledge and experience of other coaches to assist them with 411 their reflections. Reflection can be more effective when coaches have a 'critical friend' 412 whose role is to promote deeper levels of reflection (Knowles et al., 2001). Ian highlighted: 413 'our centre manager spoke with me about a change in the way we were coaching to 414 implement different styles. We also had the help of Pete Smith [pseudonym] from the FA so 415 that had an influence'. Indeed, Strean, Senecal, Howlett and Burgess (1997) argue that 416 coaches, who are provided with the opportunity to discuss their coaching issues with other's 417 develop more effective coaching strategies in which to deal with their coaching issues, as 418 Jude and Lee both highlighted: Talking to other coaches actually helped me learn. For me, it's not just a case of being in there and doing it and then coming away and that's it and I'll automatically learn, I think the process of talking to other coaches...for example, something might happen on the Sunday or in the game, speaking to them about it and how I dealt with it and what I could do and building from their advice but more gauging me in some sort of thinking... the discussion with colleagues, the discussion with coaches is really important.

\section{Other learning and its impact on practice}

434 Throughout the longitudinal research process the coaches tapped into a range of sources that

This year again from the gaffer at the club who has passed down his stuff through to the head of coaching who I have a lot of chats with. In terms of knowledge of the sport, I've sort of improved that area from these people...I think it certainly helps in terms of understanding the sport better and having a greater knowledge of the game. So I can transfer that knowledge onto the players, one way or another. were meaningful and relevant to their own coaching practice to develop and evaluate their coaching strategies, this included other coaches at the club, research evidence, and experiences from formal coach education episodes, in particular the FA Youth Modules. All five coaches (i.e. Tony, Pete, Jude, Lee and Ian) reinforced this view noting that: 
The modules have changed people's ways of thinking they've adapted a lot of teaching and gone down the teaching route rather than a lot of instruction, instruction, instruction. I definitely made a conscious effort in terms of, I think I went down the route of seeing mistakes and trying to correct them for them and notably then they learned. I think some of the stuff on the FA modules have obviously changed the way I've thought about coaching, in terms of setting up the correct environment and saying things differently to let them learn by doing.

Talking to other coaches around the Youth Modules... opened my eyes to a few things that I didn't know and how much I was using certain coaching types or certain coaching manners. The courses have helped my knowledge. I understood some of the theory and stuff behind what was happening, or what they were trying to say, the coach, educator on the coaching course, I understand that side but actually that transfer into practise, I think helped on the Youth Module. The Youth Award certainly helped in terms of transferring that theory into some sort of ideas of the practise.

I genuinely believe my coaching has changed through the new youth modules, I think

467 The situation, whereby the critical incident or evidence from video was in conflict with the 468 coaches' network of knowledge, experiences or beliefs, has been referred in the learning 469 literature to as cognitive dissonance (Moon, 2004) or disjuncture (Jarvis, 2009). Disjuncture 470 is portrayed as a moment of potential for learning and it would seem that the coaches sought 471 a range of learning sources to change their practice and to maintain accordance or harmony in 472 their biography (Jarvis, 2009) (e.g. FA Youth Awards, teaching qualification, social media, 473 internet, observation of and discussion with other coaches). However, there is a danger in 474 picking out ideas that fit into beliefs and collecting evidence to confirm the decision, while 475 rejecting concepts that maybe more challenging. This has been labelled 'safe simulation', and 
476 is reported relatively commonly in the literature (e.g. Abraham et al., 2006; Cushion et al.,

477 2003). This approach can enable practitioners to adopt seemingly novel changes to their

478 coaching while preserving their underlying assumptions about coaching and norms of

479 practice (Light \& Robert, 2010). Another significant issue with this learning approach is the

480 potential for rejecting or disregarding information that could otherwise be highly valuable.

\section{Implications for Practice}

483 Video-based reflection helped coaches increase their self-awareness, change behaviour and

484 provided the trigger for learning. Relying on coaches' thoughts and perceptions alone does 485 not provide accurate measurements of what coaches actually do (Partington \& Cushion, 486 2013). For coaches to become more self-actualising practitioners requires that they think 487 more critically about their practices (Butler, 2005). McAllister et al. (2000) highlight this 488 point as they recognize the lack of congruence between stated beliefs and action, and 489 subsequently call for educators and practitioners to pay attention to this gap. In other words, 490 use of video-based reflection helped make vital learning processes more explicit, facilitating 491 coaches' judgements of what works, as well as making them more aware of their practice in 492 context.

493 In the present study video-based reflection provided the coaches with the mechanism 494 to recognise their actual coaching practice. If coaches are unable to accurately recall their 495 coaching practices through their own subjective experiences, alternative methods are needed 496 which present them with the means to reflect on actual practice (Carson, 2008). Furthermore, 497 the use of video-based reflection could also potentially permit coaches to reflect at a deeper 498 level with appreciation of the nuanced, intricate, and complex nature of coaching (Harvey et 499 al., 2010; Jones \& Wallace, 2005) and address issues of practice that have become deep500 rooted in a non-reflective manner (Thompson \& Pascal, 2012). Consistent with the work of 501 Douglas and Carless (2008), the results here suggested that coaches' were open to changing 502 perspectives as the scenarios unfolded, allied to having time to reflect upon and discuss 503 identified issues with others. This could be interpreted as a good starting point for developing 504 more open mindedness in coaches, thus holding the potential to enhance the change process 505 in coach education and to develop more reflective practitioners. As the longitudinal nature of 506 this research has demonstrated change to coaches' practice is a long-term process and will not 507 happen quickly. In addition, whilst the coaches stated the positive impact of coach education 508 they found it difficult to directly link changes in specific coach behaviour to these statements. 
509 So whilst coaches may perceive these courses to have an impact, it appeared more as an

510 explanation for their practice now, rather than an indicator for the reasons for change.

511 Coach education courses have been criticised for their de-contextualised and one size

512 fits all curricula approach that does not allow for coaches to discuss issues that are most

513 pertinent to them (Nelson, Cushion \& Potrac, 2006). To develop autonomous learners who

514 are capable of taking ownership of their own learning (Taylor \& Garratt, 2010) coach

515 education should consider carefully the learning needs of individual coaches (e.g. Gilbert \&

516 Trudel, 2001; Nelson \& Cushion, 2006), and the contexts in which they coach. For coaches

517 this means engaging in an ongoing reflective process (Butler, 2006; Ghaye \& Ghaye, 1998)

518 that is situated within their knowledge and experiences. As Leamson (2000) implies, it is not

519 the doing that results in learning, but rather the thinking about the doing. The present study

520 provides evidence that the use of contextualised video-based reflection can provide a

521 mechanism for coaches to link new knowledge to their individual coaching.

522

523 Conclusion

524 Reflective thinking is not straightforward for coaches (Hughes, Lee \& Chesterfield, 2009;

525 Knowles et al., 2001). Hughes et al. (2009) argue that for reflection to impact on their

526 thinking, coaches need to be engaged within a structured reflective process. However, self-

527 reflection has been criticised because coaches' reflections are limited by their own knowledge

528 (Hughes et al., 2009), and restricted by their coaching beliefs (Parajes, 1992). In other words,

529 coaches only reflect on issues they are aware of and are unable to reflect beyond their

530 consciousness. The use of video (Carson, 2008) and discussion with other coaches (Knowles

531 et al., 2001) offers the potential of enabling deeper, more critical levels of reflection. Indeed

532 in the present study contextualised video-based reflection and discussions with others

533 (including the research process) helped the coaches develop self-awareness of their practice,

534 trigger learning, develop and reinforce new knowledge and provide examples of knowledge

535 in practice.

536

537 References

538 Abraham, A., Collins, D., \& Martindale, R. (2006). The coaching schematic: Validation

539 through expert coach consensus. Journal of Sport Sciences, 24, 549-564.

540 Baumgartner, T. A., Jackson, A. S., Mahar, M. T., \& Rowe, D. A. (2007). Measurement for

541 evaluation in physical education and exercise science (8th ed.). Boston: McGraw-Hill. 
542 Brewer, C.J., \& Jones, R.L. (2002). A five-stage process for establishing contextually valid

543 systematic observation instruments: The case of rugby union. Sport Psychologist, 16(2), 138-

544159.

545 Butler, J. (2005). TGfU pedagogy: Old dogs, new tricks and puppy school. Physical

546 Education and Sport Pedagogy, 10, 225-240.

547 Carson, F. (2008). Utilizing Video to Facilitate Reflective Practice: Developing Sports 548 Coaches. International Journal of Sports Science and Coaching, 3(3), 381-390.

549 Cassidy, T. (2010). Understanding athlete learning and coaching practice: Utilising 'practice 550 theories' and 'theories of practice'. In J. Lyle, \& C. Cushion (Eds.), Sports Coaching: 551 Professionalisation and Practice (pp. 177-191). London: Elsevier.

552 Christensen, D. (2011). Disagreement, question-begging and epistemic self-criticism.

553 Philosophers imprint, 11(6), 1-22.

554 Creswell, J. W. (2003). Research design: Qualitative, quantitative, and mixed methods 555 approaches (2nd ed.). Thousand Oaks, CA: Sage.

556 Cushion, C. J., Ford, P., \& A. M. (2012). Coach behaviour and practice structures in youth

557 soccer: Implications for talent development. Journal of Sport Sciences, 30(15), 1631-1641.

558 Cushion, C. J., Harvey, S., Muir, R., \& Nelson, L. (2012). Developing the coach analysis and

559 intervention system (CAIS): Establishing validity and reliability of a computerized systematic

560 observation instrument. Journal of Sport Sciences, 30(1), 201-216.

561 Cushion, C. J., \& Jones, R. L. (2006). Power, discourse and symbolic violence in professional 562 youth soccer: The case of Albion FC. Sociology of Sport Journal, 23, 142-161.

563 Cushion, C. J., Armour, K. M., Jones, R. L. (2003). Coach education and continuing

564 professional development: Experience and learning to coach. Quest, 55, 215-230.

565 Davis, B., \& Sumara, D. (1997). Cognition, complexity and teacher education. Harvard 566 Educational Review, 67, 105-125.

567 Douglas, K., \& Carless, D. (2008). Using Stories in Coach Education. International Journal 568 of Sports Science and Coaching, 3(1), 33-49.

569 Eraut, M. (2000). Non-formal learning and tacit knowledge in professional work. British 570 Journal of Educational Psychology, 70, 113-136.

571 Erickson, K., Côté, J., \& Fraser-Thomas, J. (2007). The sport experiences, milestones, and 572 educational activities associated with the development of high performance coaches. The 573 Sport Psychologist, 21, 302-316. 
574 Ford, P. R., Yates, I., \& Williams, A. M. (2010). An analysis of practice activities and 575 instructional behaviours used by youth soccer coaches during practice: Exploring the link 576 between science and application. Journal of Sports Sciences, 28(5), 483-495.

577 Ghaye, T. (2001). Reflection: Principles and practices. Faster, Higher, Stronger, 10, 9-11.

578 Ghaye, T., \& Ghaye, K. (1998). Teaching and learning through critical reflective practice. 579 London: Fulton Publishers.

580 Gilbert, W., \& Trudel, P. (2001). Learning to coach through experience: Reflection in model 581 youth sport coaches. Journal of Teaching in Physical Education, 21, 16-34.

582 Gilbert, W., \& Trudel, P. (2005). Learning to coach through experience: Conditions that 583 influence reflection. Physical Educator, 62, 32-44.

584 Gilbert, W.D., \& Trudel, P. (2004). Analysis of coaching science research published from 585 1970- 2001. Research Quarterly for Sport and Exercise, 75, 388-399.

586 Gilbert, W., \& Trudel, P. (2006). The coach as a reflective practitioner. In R. Jones (Ed.), The 587 sports coach as educator: Reconceptualising sports coaching (pp. 113-127). London, UK:

588 Routledge.

589 Glaser, B.G, \& Strauss, A.L. (1967). The discovery of grounded theory: strategies for 590 qualitative research. New York: Aldine.

591 The Premier League (2011). Elite Player Performance Plan. London: The Premier League.

592 Trudel, P., Gilbert, W., \& Tochon, F.V. (2001). The use of video to study pedagogical 593 interactions in sport. International Journal of Applied Semiotics, 2(1-2), 89-112.

594 Hager, P., \& Hodkinson, P. (2009). Moving beyond the metaphor of transfer of learning. 595 British Educational Research Journal, 35(4), 619-638.

596 Harvey, S., Cushion, C. J., Cope, E., \& Muir, B. (2013). A season long investigation into the 597 coaching behaviours of three collegiate coaches as a function of practice state. Sports 598 Coaching Review. 2, 13-32.

599 Harvey, S., Cushion, C. J., \& Massa-Gonzalez, A. N. (2010). Learning a new method: 600 Teaching Games for Understanding in the coaches' eyes. Physical Education and Sport 601 Pedagogy, 15(4), 361-382.

602 Hughes, C., Lee, S., \& Chesterfield, G. (2009). Innovation in sports coaching: the 603 implementation of reflective cards. Reflective Practice, 10(3), 367-384.

604 Irwin, G., Hanton, S., \& Kerwin, D. (2004). Reflective practice and the origins of elite 605 coaching knowledge. Reflective Practice, 5, 426-442.

606 Jarvis, P. (2009). Learning to be a person in society. London: Routledge. 
607 Jones, R. L., Armour, K. M. \& Potrac, P. (2004). Sports coaching cultures: from practice to 608 theory. London: Routledge.

609 Jones, R. L., \& Wallace, M. (2005). Another bad day at the training ground: Coping with 610 ambiguity in the coaching context. Sport, Education and Society, 10(1), 119-134.

611 Knowles, Z., Gilbourne, D., Borrie, A., \& Neville, A. (2001). Developing the reflective 612 sports coach: A study exploring the processes of reflection within a higher education 613 coaching programme. Reflective Practice, 2, 185-207.

614 Leamson, R. (2000). Learning as Biological Brain Change. Change, 32(6), 34-40.

615 Leduc, M., Culver, D. M., \& Werthner, P. (2012). Following a coach education programme:

616 Coaches' perceptions and reported actions. Sports Coaching Review, 1(2), 135-150.

617 Onwuegbuzie, A.J., \& Leech, N.L. (2007). A call for qualitative power analyses. Quality and 618 Quantity: International Journal of Methodology, 41, 105-121.

619 Light, R. (2008). Complex learning theory - Its epistemology and its assumptions about 620 learning: implications for physical education. Journal of Teaching in Physical Education, 27, $621 \quad 21-37$.

622 Light, R. L., Evans, J., Harvey, S., \& Hassanin, R. (2015). Advances in rugby coaching: An 623 holistic approach, London: Routledge.

624 Light, R., \& Robert, J. E. (2010). The impact of Game Sense on elite level level rugby 625 coaches' practice: A question of pedagogy. Physical Education and Sport Pedagogy, 15(2) $626 \quad 103-115$.

627 Loughran, J. J. (2002). Effective reflective practice: In search of meaning in learning about 628 teaching. Journal of Teacher Education, 53(1), 33-43.

629 McCallister, S. G., Blinde, E. M., \& Weiss, W. M. (2000). Teaching values and 630 implementing philosophies: Dilemmas of the coach. Physical Educator, 57(1), 35-45.

631 Meeûs, M., Serpa, S., \& De Cuyper, B. (2010). The effects of video feedback on coaches' 632 behavior and the coach-athlete relationship. Journal of Clinical Sport Psychology, 4, 323633340.

634 Moon, J. (2004). A handbook of reflective and experiential learning. London: Routledge.

635 Morgan, D.L. (2007). Paradigms lost and paradigms regained. Journal of Mixed Methods, $6361(1), 48-76$.

637 Nelson, L., \& Cushion, C. J. (2006). Reflection in coach education: The case of the NGB 638 coaching certificate. The Sport Psychologist, 20(2), 174-183.

639 Nelson, L., Cushion, C., \& Potrac, P. (2006). Formal, nonformal and informal coach learning: 640 A holistic conceptualisation. International Journal of Coaching Science, 1(3), 247-259. 
641 Pajares, M.F. (1992). Teachers' beliefs and educational research: cleaning up a messy

642 construct. Review of Educational Research, 62(3), 307-333.

643 Partington, M., Cushion, C. J. \& Harvey, S. (2013). An investigation of the effect of athletes'

644 age on the coaching behaviours of professional top-level youth soccer coaches. Journal of

645 Sport Sciences, 32(5), 403-414.

646 Partington, M. \& Cushion, C. J. (2013). An investigation of the practice activities and

647 coaching behaviours of professional top-level youth soccer coaches. Scandinavian Journal of

648 Medicine and Science in Sports, 23(3), 373-382.

649 Potrac, P., \& Cassidy, T. (2006). The coach as 'a more capable other'. In R. Jones (Ed.), The

650 sports coach as educator: Reconceptualising sports coaching (pp. 39-50). London:

651 Routledge.

652 Potrac, P., Jones, R., \& Armour, K. (2002). "It's all about getting respect”: The coaching

653 behaviours of a top-level English football coach. Sport, Education and Society, 7(2), 183-

654202.

655 Roderick, M. (2006). The work of professional football: A labour of love? Abingdon:

656 Routledge.

657 Schön, D. (1983). The reflective practitioner: How professionals think in action. San658 Francisco, CA: Harper Collins.

659 Stark, S. \& Torrance, H. (2005). Case study. In B. Somekh \& C. Lewin (Eds.), Research 660 Methods in the Social Sciences (pp. 33-40). Thousand Oaks, CA: Sage.

661 Strean, W. B., Senecal, K. L., Howlett, S. G., \& Burgess, J. M. (1997). Xs and Os and what

662 the coach knows: Improving team strategy through critical thinking. The Sport Psychologist, $66311,243-256$.

664 Thompson, N., \& Pascal, J. (2012). Developing critically reflective practice. Reflective 665 Practice: International and Multidisciplinary perspectives. 13(2) 311-325.

666 van der Mars, H. (1989). Observer reliability: Issues and procedures. In P. W. Darst, D. B.

667 Zakrajsek, \& V. H. Mancini (Eds.), Analyzing physical education and sport instruction (pp.

668 53-80). Champaign, IL: Human Kinetics Publishers.

669 Varela, F.J., Thompson, E., \& Rosch, E. (1991). The embodied mind: Cognitive science and

670 human experience. Cambridge, MA: MIT Press.

671 White, R.T. (1988). Learning science. London: Blackwell.

672 Williams, A.M., \& Hodges, N. (2005). Practice, instruction and skill acquisition in soccer:

673 challenging tradition. Journal of Sports Sciences, 23(6), 637-650. 
674 Yin, R. (1994). Case study research: Design and methods (2nd ed.). Beverly Hills, CA: Sage 675 Publishing.

676

677

678

679

680

681

682

683

684

685

686

687

688

689

690

691

692

693

694

695

696

697

698

699

700

701

702

703

704

705

706 